\begin{tabular}{|c|c|}
\hline \multirow{3}{*}{ 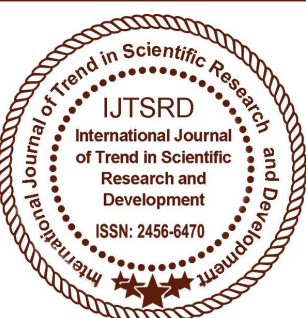 } & $\begin{array}{l}\text { International Journal of Trend in Scientific } \\
\text { Research and Development (IJTSRD) }\end{array}$ \\
\hline & International Open Access Journal \\
\hline & ISSN No: 2456 - 6470 | www.ijtsrd.com | Volume - 2 | Issue - 5 \\
\hline
\end{tabular}

\title{
Hybrid Techniques of Genetic Algorithm for Inventory of Auto Industry Model for Deteriorating Ttems with Two Warehouses
}

\author{
Ajay Singh Yadav', Navin Ahlawat ${ }^{2}$, Sharat Sharma ${ }^{3}$ \\ ${ }^{1}$ Assistant Professor, Department of Mathematics, ${ }^{2}$ Professor, Department of Computer Science, \\ ${ }^{3}$ Assistant Professor, Department of Business Administration \\ ${ }^{1,2,3}$ SRM Institute of Science and Technology (Formerly Known as SRM University), \\ Delhi-NCR Campus, Ghaziabad, Uttar Pradesh, India
}

\section{ABSTRACT}

In this Paper Hybrid techniques are the integration of various soft computing techniques that synergizes the strength and weakness of an individual technique with the other therefore the overall performance of such techniques working in unison is increased. A deterministic inventory of Auto industry model has been developed for deteriorating items of Auto industry having a ramp type demand with the effects of inflation with two-storage of Auto industry facilities using Genetic Algorithms. Here, we assumed that the inventory of Auto industry holding cost in RW is higher than those in OW. Shortages in inventory of Auto industry are allowed and partially backlogged and it is assumed that the inventory of Auto industry deteriorates over time at a variable deterioration rate using Genetic Algorithms. The effect of inflation of Auto industry has also been considered for various costs associated with the inventory of Auto industry system. Cost minimization technique is using Genetic Algorithms to get the expressions for total cost and other parameters.

Keywords: Two-warehouses, deterministic inventory, deteriorating items and Genetic Algorithms

\section{INTRODUCTION}

Many researchers extended the EOQ model to timevarying demand patterns. Some researchers discussed of inventory of Auto industry models with linear trend in demand. The main limitations in linear-time varying demand rate is that it implies a uniform change in the demand rate per unit time. This rarely happens in the case of any commodity in the market.
In recent years, some models have been developed with a demand rate that changes exponentially with time. For seasonal products like clothes, Air conditions etc. at the end of their seasons the demand of these items is observed to be exponentially decreasing for some initial period. Afterwards, the demand for the products becomes steady rather than decreasing exponentially. It is believed that such type of demand is quite realistic. Such type situation can be represented by ramp type demand rate.

An important issue in the inventory theory is related to how to deal with the unfulfilled demands which occur during shortages or stock outs. In most of the developed models researchers assumed that the shortages are either completely backlogged or completely lost. The first case, known as backordered or backlogging case, represent a situation where the unfulfilled demand is completely back ordered. In the second case, also known as lost sale case, we assume that the unfulfilled demand is completely lost.

Furthermore, when the shortages occur, some customers are willing to wait for backorder and others would turn to buy from other sellers. In many cases customers are conditioned to a shipping delay and may be willing to wait for a short time in order to get their first choice. For instance, for fashionable commodities and high-tech products with short product life cycle, the willingness of a customer to wait for backlogging is diminishing with the length of the waiting time. Thus the length of the waiting time for the next replenishment would determine whether 
the backlogging would be accepted or not. In many real life situations, during a shortage period, the longer the waiting time is, the smaller is the backlogging rate would be. Therefore, for realistic business situations the backlogging rate should be variable and dependent on the waiting time for the next replenishment. Many researchers have modified inventory policies by considering the "time proportional partial backlogging rate".

\section{Related Works}

Zangwill (1966) developed a production multi period production scheduling model with backlogging. Inventory models with a mixture of backorders and lost sales were formulated by Montgomery et al. (1973). Economic production lot size model for deteriorating items with partial backordering was suggested by Wee (1993). A comparison of two replenishment strategies for the lost sales inventory model was presented by Donselaar et al. (1996). Time-limited free back-orders EOQ model was formulated by Abound and Sfairy (1997).Chang and Dye (1999) developed an inventory model in which the proportion of customers who would like to accept backlogging is the reciprocal of a linear function of the waiting time. Papachristos and Skouri (2000) established a partially backlogged inventory model in which the backlogging rate decreases exponentially as the waiting time increases. An EOQ inventory model for items with Weibull distribution deterioration rate and ramp type demand was formulated by $\mathrm{Wu}$ (2001). Shortages in inventory were allowed and assumed to be partially backlogged. Teng et al. (2002) presented an optimal replenishment policy for deteriorating items with time-varying demand and partial backlogging. An EOQ model for deteriorating items with time-varying demand and partial backlogging was suggested by Teng et al. (2003). Chu and Chung (2004) discussed the sensitivity of the inventory model with partial backorders. An EOQ model with time varying deterioration and linear time varying demand over finite time horizon was proposed by Ghosh and Chaudhuri (2005). Shortages in inventory were allowed and partially backlogged with waiting time dependent backlogging rate. Optimal ordering policy for deteriorating items with partial backlogging was formulated by Ouyang et al. (2006) when delay in payment was permissible. Dye (2007) proposed joint pricing and ordering policy for deteriorating inventory. Shortages in inventory were allowed and partial backlogged. An inventory lot-size model for deteriorating items with partial backlogging was formulated by Chern et al. (2008). Authors have taken time value of money in to consideration. The demand was assumed to fluctuating function of time and the backlogging rate of unsatisfied demand was a decreasing function of the waiting time.

Taleizadeh AA, et.al. (2008). developed Optimizing Multi-Product Multi-Constraint Inventory Control Systems with Stochastic Replenishment and an EOQ Joint Replenishment Policy to Supply Expensive Imported Raw Materials with Payment in Advance. multi products, multi constraints newsboy problem with batch order and discount.

Taleizadeh AA, et.al (2009) extended A Particle Swarm Optimization Approach for Constraint Joint Single Buyer-Single Vendor Inventory Problem with Changeable Lead-Time and (r,Q) Policy in Supply Chain. developing a Multiproduct Newsboy Problem with a Hybrid Method of Fuzzy Simulation and Simulated Annealing. a Hybrid Method of Pareto, TOPSIS and Genetic Algorithm to Optimize MultiProduct Multi-Constraint Inventory Control Systems with Random Fuzzy Replenishments. optimizing multi product multi constraints Bi-objective newsboy Problem with discount by Hybrid Method of Goal Programming and Genetic Algorithm. a Hybrid Method to Optimize Bi-Objective Single Period Newsboy Problem with Fuzzy Cost and Incremental Discount. multi-product multi-constraint inventory control systems with stochastic replenishment and discount under Fuzzy Purchasing Price and Holding Costs. multi-product multi-constraint inventory control systems with stochastic period length and total discount under fuzzy purchasing price and holding costs. Optimizing multi-product multi-constraint biobjective newsboy problem with discount by hybrid method of goal programming and genetic algorithm. a harmony search algorithm to optimize chance constraint stochastic inventory systems with dynamic demand. joint replenish-up-to multi products EOQ with fuzzy rough demand. N. Jawahar and A. N. Balaji (2009) developed A genetic algorithm for the two-stage supply chain distribution problem associated with a fixed charge. Haixin Zhang et.al. (2013) suggested A modified multi-criterion optimization genetic algorithm for order distribution in collaborative supply chain. S. P. Nachiappan and N. Jawahar (2007) developed A genetic algorithm for optimal operating parameters of VMI system in a twoechelon supply chain. Z. H. Che and C. J. Chiang (2010) suggested a modified Pareto genetic algorithm 
for multi-objective build-to-order supply chain planning with product assembly. Keyvan Sarrafha et.al. (2015) developed A bi-objective integrated procurement, production, and distribution problem of a multi-echelon supply chain network design: A new tuned MOEA. Ata Allah Taleizadeh et.al. (2011) extended Multiple-buyer multiple-vendor multiproduct multi-constraint supply chain problem with stochastic demand and variable lead-time: A harmony search algorithm. Wei-Chang Yeh and Mei-Chi Chuang (2011) suggested Using multi-objective genetic algorithm for partner selection in green supply chain problems. S.A. Torabi, et.al. (2006) extended A hybrid genetic algorithm for the finite horizon economic lot and delivery scheduling in supply chains. Pavan Kumar Naraharisetti et.al. (2007) suggested Optimal supply chain redesign using genetic algorithm. Moon-Chan Kim et.al. (2008) developed Forward-backward analysis of RFIDenabled supply chain using fuzzy cognitive map and genetic algorithm. Partha Guchhait et.al. (2013) extended A production inventory model with fuzzy production and demand using fuzzy differential equation: An interval compared genetic algorithm approach. U. K. Bera et.al. (2012) extended Inventory model with fuzzy lead-time and dynamic demand over finite time horizon using a multiobjective genetic algorithm. Ata Allah Taleizadeh et. al. (2009) suggested A hybrid method of Pareto, TOPSIS and genetic algorithm to optimize multiproduct multi-constraint inventory control systems with random fuzzy replenishments. Ali Roozbeh Nia et.al. (2014) extended A fuzzy vendor managed inventory of multi-item economic order quantity model under shortage: An ant colony optimization algorithm. Javad Sadeghi et. al. (2014) extended optimizing a hybrid vendormanaged inventory and transportation problem with fuzzy demand: An improved particle swarm optimization algorithm. Manas Kumar Maiti (2011) developed A fuzzy genetic algorithm with varying population size to solve an inventory model with credit-link ed promotional demand in an imprecise planning horizon. H. Altay Guvenir and Erdal Erel (1998) suggested Multicriteria inventory classification using a genetic algorithm. Ali Diabat (2014) extended Hybrid algorithm for vendor managed inventory system in a two-echelon supply chain. K. L. Mak et. al. (1999) developed optimal inventory control of lumpy demand items using genetic algorithms. A. K. Maiti et. al. (2006) extended An application of realcoded genetic algorithm (RCGA) for mixed integer non-linear programming in two-storage multi-item inventory model with discount policy. Kuo-Ping Lin et.al. (2010) developed A simulation of vendor managed inventory dynamics using fuzzy arithmetic operations with genetic algorithms. Sung-Pil Hong and Yong-Hyuk Kim (2009) suggested A genetic algorithm for joint replenishment based on the exact inventory cost. Manas Kumar Maiti and Manoranjan Maiti (2007) extended Two-storage inventory model with lot-size dependent fuzzy lead-time under possibility constraints via genetic algorithm. Arindam Roy et. al. (2009) developed a production inventory model with stock dependent demand incorporating learning and inflationary effect in a random planning horizon: A fuzzy genetic algorithm with varying population size approach. S. M. Disney et. al. (2000) suggested Genetic algorithm optimisation of a class of inventory control systems.

\section{Assumptions and Notations}

In developing the mathematical model of the inventory system the following assumptions are being made:

A single item is considered over a prescribed period $\mathrm{T}$ units of time.

The demand rate of Auto industry $\mathrm{D}(\mathrm{t})$ at time $\mathrm{t}$ is deterministic and taken as a ramp type function of time i.e. $D(t)=\eta e^{-\gamma\{t-(t-\psi) H(t-\psi)\}}, \eta>0, \gamma>0$

The replenishment rate is infinite and lead-time is zero.

When the demand for goods is more than the supply.

The variable rate of deterioration in both warehouse is taken as $\beta(\mathrm{t})=\beta \mathrm{t}$. Where $0<\beta<<1$ and only applied to on hand inventory.

No replacement or repair of deteriorated items is made during a given cycle.

The owned warehouse of Auto industry (OW) has a fixed capacity of $\mathrm{W}$ units; the rented warehouse of Auto industry (RW) has unlimited capacity.

The goods of OW are consumed only after consuming the goods kept in RW.

In addition, the following notations are used throughout this paper:

$\mathrm{I}_{\mathrm{ow}}(\mathrm{t}) \quad$ The inventory of Auto industry level in OW at any time $t$.

$\mathrm{I}_{\mathrm{rw}}(\mathrm{t}) \quad$ The inventory of Auto industry level in RW at any time $t$.

$\mathrm{C}_{\mathrm{W}} \quad$ The capacity of the own warehouse of Auto industry. 
International Journal of Trend in Scientific Research and Development (IJTSRD) ISSN: 2456-6470

$\mathrm{T}$

$\theta$

$\mathrm{H}_{\mathrm{O}} \quad$ The holding cost of Auto industry per unit $\mathrm{C}_{1}$ per unit time in OW.

$\mathrm{H}_{\mathrm{R}} \quad$ The holding cost of Auto industry per unit A per unit time in RW. where $\mathrm{H}_{\mathrm{O}}<\mathrm{H}_{\mathrm{R}}$
The deterioration cost of Auto industry per unit.

$\mathrm{S}_{\mathrm{C}} \quad$ The shortage cost of Auto industry per unit per unit time.

The opportunity cost of Auto industry due to lost sales.

The replenishment cost of Auto industry per order.

\section{Formulation and solution of the model}

The inventory levels of Auto industry at OW of Auto industry are governed by the following differential equations:

$\frac{d I_{o w}(t)}{d t}=-\beta(t) I(t)$

$\frac{d I_{o w}(t)}{d t}+\beta(t) I(t)=-\eta e^{-\gamma \psi}$,

And

$\frac{d I_{o w}(t)}{d t}=-\eta e^{-\gamma \psi} e^{-\alpha t}$,

with the boundary conditions,

$\mathrm{I}_{0 \mathrm{~W}}(0)=\mathrm{C}_{\mathrm{W}}$ and $\mathrm{I}\left(\mathrm{t}_{1}\right)=0$

$$
\mathrm{t}_{1} \leq \mathrm{t} \leq \mathrm{T}
$$

The solutions of equations (1), (2) and (3) are given by

$I_{o w}(t)=C_{W} e^{-\beta t^{2} / 2}$,

$0 \leq t<\psi$

$I_{\text {ow }}(t)=\eta e^{-\gamma \psi}\left\{\left(t_{1}-t\right)+\beta \frac{\left(t_{1}^{3}-t^{3}\right)}{6}\right\} e^{-\beta t^{2} / 2}, \quad \psi \leq t \leq t_{1}$

And $I_{o w}(t)=\frac{\eta}{\alpha} e^{-\gamma \psi}\left\{e^{-\alpha t}-e^{-\alpha t_{1}}\right\}, \quad \mathrm{t}_{1} \leq \mathrm{t} \leq \mathrm{T}$

respectively.

The inventory level of Auto industry at RW of Auto industry is governed by the following differential equations:

$\frac{d I_{r w}(t)}{d t}+\beta(t) I(t)=-\eta e^{-\gamma t}, \quad 0 \leq t<\psi$

With the boundary condition $\mathrm{I}_{\mathrm{rw}}(0)=0$, the solution of the equation (8) is

$I_{r w}(t)=\eta\left\{(\psi-t)-\frac{\gamma}{2}\left(\psi^{2}-t^{2}\right)+\frac{\beta}{6}\left(t_{1}^{3}-t^{3}\right)\right\} e^{-\beta t^{2} / 2}, \quad \psi \leq t \leq t_{1}$ 
Due to continuity of $I_{o}(t)$ at point $t=\mu$, it follows from equations (5) and (6), one has

$$
\begin{aligned}
& C_{W} e^{-\beta \psi^{2} / 2}=\eta e^{-\gamma \psi}\left\{\left(t_{1}-\psi\right)+\beta \frac{\left(t_{1}^{3}-\psi^{3}\right)}{6}\right\} e^{-\beta \psi^{2} / 2} \\
& C_{W}=\eta e^{-\gamma \psi}\left\{\left(t_{1}-\psi\right)+\beta \frac{\left(t_{1}^{3}-\psi^{3}\right)}{6}\right\}
\end{aligned}
$$

The total average cost consists of following elements:

I. Ordering cost of Auto industry per cycle $=\mathrm{A}$

II. Holding cost of Auto industry per cycle $\left(\mathrm{H}_{1}\right)$ in $\mathrm{OW}$

$H_{1}=H_{O}\left[\int_{0}^{\psi} I_{0 w}(t) e^{-\theta t} d t+\int^{t_{1}} I_{0 w}(t) e^{-\theta(\psi+t)} d t\right]$

III. Holding cost of Auto industry per cycle $\left(\mathrm{C}_{\mathrm{HR}}\right)$ in $\mathrm{RW}$

$$
H_{2}=H_{R}\left[\int_{0}^{\psi} I_{r w}(t) e^{-\theta t} d t\right]
$$

IV. Cost of deteriorated units of Auto industry per cycle $\left(C_{D}\right)$

$=D_{C}\left[\int_{0}^{\psi} \beta t I_{r w}(t) e^{-\theta t} d t+\int_{0}^{\psi} \beta t I_{0 w}(t) e^{-\theta t} d t+\int_{\psi}^{t_{1}} \beta t I_{0 w}(t) e^{-\theta(t+\psi)} d t\right]$

V. Shortage cost of Auto industry per cycle $\left(C_{S}\right)$

$=S_{C}\left[\int_{t_{1}}^{T}-I_{0 w}(t) e^{-\theta\left(t_{1}+t\right)} d t\right]$

VI. Opportunity cost of Auto industry due to lost sales per cycle $\left(\mathrm{C}_{0}\right)$

$=C_{1} \int_{t_{1}}^{T} \eta\left(1-e^{-\alpha t}\right) e^{-\gamma \psi} e^{-\theta\left(t_{1}+t\right)} d t$

Therefore, the total average cost per unit time of our model is obtained as follows 
$\mathrm{K}\left(\mathrm{t}_{1}, \mathrm{~T}\right)=\frac{1}{\mathrm{~T}}[$ Ordering cost of Auto industry + Holding cost of Auto industry in OW+ Holding cost of Auto industry in RW+ Deterioration cost of Auto industry + Shortage cost of Auto industry + Opportunity cost of Auto industry $]=\frac{\mathrm{R}\left(\mathrm{t}_{1}, \mathrm{~T}\right)}{\mathrm{T}}$ (say)

$$
\begin{aligned}
& K\left(t_{1}, T\right)=\frac{1}{T}\left\{\eta+H_{O}\left\{C_{W}\left(\psi-\frac{\theta \psi^{2}}{2}-\frac{\beta \psi^{3}}{6}\right)+\eta e^{-\gamma(\psi+\theta)}\left[\frac{t_{1}^{2}}{2}-\frac{\theta t_{1}^{3}}{6}+\frac{\beta t_{1}^{4}}{12}-\frac{\theta \beta}{20} t_{1}^{5}\right.\right.\right. \\
& -\frac{\psi}{2}\left(2 t_{1}-\psi\right)-\frac{\beta \psi}{24}\left(4 t_{1}^{3}-\psi^{3}\right)+\frac{\theta \psi^{2}}{6}\left(3 t_{1}-2 \psi\right)+\frac{\theta \beta \psi^{2}}{30}\left(5 t_{1}^{3}-3 \psi^{3}\right)+ \\
& \left.\left.\frac{\beta \psi^{3}}{24}\left(4 t_{1}-3 \psi\right)\right]\right\}+H_{R} \eta\left[\frac{\psi^{2}}{2}-\frac{(3 \gamma+\theta)}{6} \psi^{3}+\left(\frac{\beta}{12}+\frac{\gamma \theta}{8}\right) \psi^{4}-\left(\frac{\theta \beta}{20}-\frac{\gamma \beta}{30}\right) \psi^{5}\right] \\
& +D_{C} \beta\left\{\left[\eta\left(\frac{1}{6} \psi^{3}-\left(\frac{\gamma}{4}+\frac{\theta}{12}\right) \psi^{4}+\left(\frac{\beta}{40}+\frac{\theta \gamma}{15}\right) \psi^{5}-\left(\frac{\theta \beta}{36}-\frac{\gamma \beta}{24}\right) \psi^{6}\right)\right]\right. \\
& +Q\left(\frac{\psi^{2}}{2}-\frac{\theta \psi^{3}}{3} \frac{\beta \psi^{4}}{8}\right)+\eta e^{-\psi(\gamma+\theta)}\left(\frac{t_{1}^{3}}{6}-\frac{\theta t_{1}^{4}}{12}+\frac{\beta t_{1}^{5}}{40}-\frac{\theta \beta t_{1}^{6}}{36}-\frac{\psi^{2}}{6}\right. \\
& \left(3 t_{1}-2 \psi\right)-\frac{\beta \psi^{2}}{60}\left(5 t_{1}^{3}-2 \psi^{3}\right)-\frac{\theta \psi^{3}}{12}\left(4 t_{1}-3 \psi\right)-\frac{\theta \beta \psi^{3}}{36}\left(2 t_{1}^{3}-\psi^{3}\right) \\
& \left.\left.-\frac{\beta \psi^{4}}{40}\left(5 t_{1}-4 \psi\right)\right]\right\}+\frac{\eta S_{C} e^{-\left(\theta t_{1}+\lambda \psi\right)}}{\alpha \theta(\alpha+\theta)}\left[\alpha e^{-(\alpha+\theta) t_{1}}+e^{-\theta T}\left\{\theta e^{-\alpha T}-(\alpha+\theta) e^{-\alpha t_{1}}\right\}\right] \\
& +\frac{C_{1} \eta e^{-\left(\gamma \psi+\theta t_{1}\right)}}{\theta(\alpha+\theta)}\left[e^{-\theta t_{1}}\left\{(\alpha+\theta)-\theta e^{-\alpha t_{1}}\right\}-e^{-\theta T}\left\{(\alpha+\theta)-\theta e^{-\alpha T}\right\}\right]
\end{aligned}
$$

\section{Genetic Algorithms}

The basic concepts were developed by Holland, while the practicality of using the GA to solve complex problems was demonstrated. Genetic Algorithms (GAs) is a soft computing approach. GA is a maximization process. The problem it addresses usually has a very large search space with probable multiple local maxima inside it. The GA process has to ensure that it is not trapped at local maxima, so that at the end of the process it may find the global maxima even if the global maximum is not returned, we may expect a close approximation of it as the outcome of the GA process To achieve this, GA works on a set of solutions to the given problem instance, and evolves it through a number of generations. The evolution process stops when some predefined termination condition is satisfied. At each intermediate stage, the old generation is replaced by the new generation. The individuals of the population of a generation are processed with the help of a number of GA operators in such a way that the quality of the new generation, in general is improved in comparison with old generation. In this way we obtain better and better solution will be returned by the GA process.

\section{Procedure Basic GA}

Step 1 :- Initialize the population. Call this the current population.

Step 2 :- Repeat step 3 through step 5 till termination condition is satisfied. 
Step 3 :- Apply selection operation on the current population to obtain the mating pool.

Step 4 :- Apply crossover and mutation operators $n$ for the matting pool to generate the new Population.

Step 5 :- Replace the current population by the new population.

Step 6 :- Return the best solution of the current population.

\section{Numerical Illustration}

To illustrate the model numerically the following parameter values are considered.
$\eta=50$ units,
$\mathrm{A}=$ Rs. 100 per order,
$\theta=0.05$ unit,
$\mathrm{H}_{\mathrm{O}}=$ Rs. 3.0 per unit per year,
$\gamma=0.2$ unit,
$\mathrm{H}_{\mathrm{W}}=$ Rs. 10.0 per unit,
$\beta=0.002$ unit,
$\mathrm{S}_{\mathrm{C}}=$ Rs. 12.0 per unit per year,
$\Psi=0.2$ year,
$\mathrm{C}_{1}=$ Rs. 4.0 per unit,
$\alpha=0.1$ unit,
$\mathrm{T}=1$ year,

Then for the minimization of total average cost and with help of software. the optimal policy can be obtained such as:

$\mathrm{t}_{1}=0.799224$ year, $\mathrm{S}=38.597235$ units and $\mathrm{K}=$ Rs.158.115354 per year.

Table: - 1 Best results of purpose function by different algorithms for Maximum demand

\begin{tabular}{|c|c|c|c|c|c|c|}
\hline \multirow{2}{*}{ Hybrid Algorithms } & \multicolumn{4}{|c|}{ Product's Maximum inventory Level } & \multirow{2}{*}{ Maximum profit (Rs.) } \\
\cline { 2 - 6 } & 1 & 2 & 3 & 4 & 5 & \\
\hline Genetic Algorithm & 721 & 801 & 371.5 & 521.1 & 780 & 3001.25 \\
\hline
\end{tabular}

\begin{tabular}{|c|c|c|c|c|c|c|}
\hline \multirow{2}{*}{ Hybrid Algorithms } & \multicolumn{4}{|c|}{ Product's Maximum inventory Level } & \multirow{2}{*}{ Maximum profit (Rs.) } \\
\cline { 2 - 6 } & 1 & 2 & 3 & 4 & 5 & \\
\hline Genetic Algorithm & 521 & 601 & 171.5 & 321.1 & 580 & 2001.25 \\
\hline
\end{tabular}

Table: - 2 Best results of purpose function by different algorithms for Minimum demand.

\section{Conclusion}

The main pillars of soft computing are Genetic Algorithms all of these have been successfully applied in isolation to solve practical problems in various fields where conventional techniques have been found inadequate. However these techniques are complementary to each other and they may work synergistically combining the strengths of more than one of these techniques as the situation may occasionally demand. Hybrid systems are systems where several techniques are combined to solve a

Therefore, numerical solution of these equations is obtained by using the software MATLAB 7.0.1.

\section{Genetic Algorithms}

Real coded, population $=90$, generations $=600$, crossover probability $=0.10$, mutation probability $=0.2$.

Since the model is integer in nature, reaching an analytical solution (if any) to the problem is difficult (Gen and Cheng, 1997). So we need to use Meta heuristic algorithms. To solve the models under metaheuristic approach, four hybrid intelligent algorithms of harmony search (Taleizadeh et al., 2009), simulated annealing (Taleizadeh, 2008, 2009), genetic algorithm Taleizadeh (2008, 2009), and particle swarm optimization (Taleizadeh et al., 2009) are used. A comparison of the results in Tables 1 and 2 for increasing and decreasing demand show that Hybrid Algorithms method performs the best.

From Tables 1 and 2, for increasing and decreasing demand functions, in term of purpose function's values Hybrid Algorithms performs better than other algorithms do. Similarly, in other examples, particle swarm optimization method has a better solution than genetic algorithm and simulated 
material product and occurrence of shortages in inventory are natural phenomenon in real situations. Inventory of Auto industry shortages are allowed in the model using Genetic Algorithms. In many cases customers are conditioned to a shipping delay, and may be willing to wait for a short time in order to get their first choice. Therefore, this concept is also taken in this model. From the numerical illustration of the model, it is observed that the period in which inventory holds of Auto industry increases with the increment in backlogging and ramp parameters while inventory period decreases with the increment in deterioration and inflation parameters of Auto industry using Genetic Algorithms. Initial inventory level of Auto industry decreases with the increment in deterioration, inflation and ramp parameters while inventory level increases of Auto industry with the increment in backlogging parameter using Genetic Algorithms. The total average cost of the system goes on increasing with the increment in the backlogging and deterioration parameters while it decreases with the increment in inflation and ramp parameters using Genetic Algorithms. The proposed model can be further extended in several ways. For example, we could extend this deterministic model in to stochastic model. Also, we could extend the model to incorporate some more realistic features, such as quantity discount or the unit purchase cost, the inventory holding cost and others can also taken fluctuating with time using Genetic Algorithms.

\section{REFERENCES}

1. Abboud, N. E. and Sfairy, R. G. (1997): Timelimited free back-orders EOQ model. Applied Mathematical Modelling (A. M. M.), 21(1), 21-25.

2. Chang, H. J. and Dye, C. Y. (1999): An EOQ model for deteriorating items with time varying demand and partial backlogging. Journal of the operational research society, 50(11), 1176-1182.

3. Chern, M. S., Yang, H. L., Teng, J. T. and Papachristos, S. (2008): Partial backlogging inventory lot-size models for deteriorating models with fluctuating demand under inflation. European Journal of operational research, 191 (1), 125-139.

4. Chu, P. and Chung, K. J. (2004): The sensitivity of the inventory model with partial backorders. European Journal of operational research, 152, 289-295.

5. Donselaar, K. V., Kok T. D., and Rutten W. (1996): Two replenishment strategies for the lost sales inventory model: A comparison. I. J. P. E., 46-47, 285-295.
6. Dye, C. Y. (2007): Joint pricing and ordering policy for a deteriorating inventory with partial backlogging. Omega, 35(2), 184-189.

7. Ghosh, S. K. and Chaudhuri, K. S. (2005): An EOQ model for a deteriorating item with trended demand and variable backlogging with shortages in all cycles. A.M.O., 7(1), 57-68.

8. Montogomery, D. C., Bazaraa, M. S., and Keshwani, A. K. (1973): Inventory models with a mixture of backorders and lost sales. Naval Research Logistics (N.R.L.), 20/2, 255-263.

9. Ouyang, L. Y., Teng, J. T. and Chen, L. H. (2006): Optimal Ordering Policy for Deteriorating Items with Partial Backlogging under Permissible Delay in Payments. Journal of Global Optimization, 34(2), 245-271.

10. Papachristos, S. and Skouri, K. (2000): An optimal replenishment policy for deteriorating items with time-varying demand and partialexponential-type backlogging. O.R.L., 27, 175184.

11. Teng, J. T., Chang, H. J., Dye, C. Y. and Hung, C. H. (2002): An optimal replenishment policy for deteriorating items with time-varying demand and partial backlogging. O.R.L., 30, 387-393.

12. Teng, J. T., Yang, H. L. and Ouyang, L. Y. (2003): On an EOQ model for deteriorating items with time-varying demand and partial backlogging. J.O.R.S., 54, 432-436.

13. Wee, H. M. (1993): Economic production lot size model for deteriorating items with partial back ordering. Computers \& Industrial Engineering, 24(3), 449-458.

14. Wu, K. S. (2001): An EOQ inventory model for items with Weibull distribution deterioration, ramp type demand rate and partial backlogging. Production planning \& control, 12(8), 787 - 793.

15. Zangwill, W. I. (1966): A deterministic multiperiod production scheduling model with backlogging. Management Science, 13, 105-119.

16. Taleizadeh A. A., Aryanezhad, M. B. and Niaki, S. T. A. (2008) Optimizing Multi-Product Multi-Constraint Inventory Control Systems with Stochastic Replenishment. Journal Applied. Science, 8: 1228-1234.

17. Taleizadeh, A. A., Niaki A A, Shafii, N. and Ghavamizadeh, R. M. (2009). A Particle Swarm Optimization Approach for Constraint Joint Single Buyer-Single Vendor Inventory Problem with Changeable Lead-Time and (r, Q) Policy in Supply Chain. International journal Advanced Manufacturing Systems, 51(9-12): 1209-1223. 